\title{
The burden of cystic fibrosis in the Medicaid population
}

This article was published in the following Dove Press journal:

ClinicoEconomics and Outcomes Research

\author{
Mariam Hassan' \\ Machaon M Bonafede ${ }^{2}$ \\ Brendan L Limone ${ }^{2}$ \\ Paul Hodgkins' \\ Gregory S Sawicki ${ }^{3}$ \\ 'Global Health Economics and \\ Outcomes Research, Vertex \\ Pharmaceuticals Incorporated, Boston, \\ MA, USA; ${ }^{2}$ Life Sciences, Truven Health \\ Analytics, Cambridge, MA, USA; \\ ${ }^{3}$ Division of Respiratory Diseases, \\ Boston Children's Hospital, Harvard \\ Medical School, Boston, MA, USA
}

Purpose: To conduct an analysis describing clinical characteristics, pulmonary exacerbation (PEx) events, and health care resource utilization among Medicaid-insured patients with cystic fibrosis (CF).

Patients and methods: A retrospective analysis of the Truven Health MarketScan ${ }^{\circledR}$ Medicaid Multi-State administrative claims database (2010-2014) was undertaken. Patients aged $\geq 6$ years with a CF diagnosis, continuously enrolled for 12 months, were identified. Demographics, comorbidities, PEx events, and health care resource utilization and costs over a 12-month enrollment period were analyzed for all patients and by age groups.

Results: In total, 1196 patients with CF aged $\geq 6$ years were identified from a sample size of approximately 10 million Medicaid patients. Mean (SD) age was 16.1 (8.8) years. A greater proportion of patients were in younger age groups (6-11 years: $35.5 \%, 12-17$ years: $29.1 \%$, $18-26$ years: $25.6 \%, 27-34$ years: $6.7 \%, \geq 35$ years: $3.2 \%$ ). Across all age groups, approximately $90 \%$ of patients had at least 1 PEx event; $50.7 \%$ of those had a PEx event involving treatment with intravenous antibiotics, and $42.8 \%$ required hospitalization. PEx recurrence was frequent: $55.7 \%$ of all patients experienced $\geq 3$ PEx events during 1 year. Mean (SD) health care expenditures during a PEx event rose with increasing age, ranging from US\$44,589 (US\$139,024) to US\$116,169 (US\$387,752). Overall health care resource utilization was high among patients with CF; $47.2 \%$ of the population required an inpatient admission, and $26.8 \%$ had subsequent hospitalizations totaling 29.1 days per year in hospital.

Conclusion: High rates of PEx, hospitalizations, and time spent in hospital demonstrate the significant health care burden of CF among Medicaid beneficiaries.

Keywords: resource utilization, length of stay, pulmonary exacerbations

\section{Plain language summary}

This study analyzed data from a health care claims database (the Truven Health MarketScan ${ }^{\circledR}$ Medicaid Multi-State administrative claims database) to examine the burden of the disease among patients with cystic fibrosis in the US Medicaid population (2010-2014). Patients aged $\geq 6$ years were assessed to see if they had the following: pulmonary exacerbation (PEx), admission to hospital, treatment with antibiotics, or use of any kind of health care resource. In addition to the resource utilization associated with PEx, the financial burden to the healthcare system was also considered. It was found that there were high rates of recurrent PEx among patients on Medicaid leading to more hospitalizations per year, with longer stays in the hospital, and a need for treatment with intravenous antibiotics. The number of PEx events in a year was found to be approximately 2 or 3 (even in younger patients). More than half of the patient population had $\geq 3 \mathrm{PEx}$ events per year. The findings from this study are similar to those seen in
Global Health Economics and Outcomes

Research, Vertex Pharmaceuticals Incorporated, 50 Northern Avenue, Boston, MA 02210 , USA

Tel + I 6179617003

Email Mariam_Hassan@vrtx.com 
other assessments and show that PEx result in long and numerous stays in the hospital accompanied by elevated health care costs. Therefore, treatment strategies to prevent PEx are necessary to help this patient population.

\section{Introduction}

$\mathrm{CF}$ is a rare progressive genetic disease caused by defects in the CFTR protein arising from mutations in the CFTR gene. The defect in CFTR protein causes complications in multiple organs, including the lungs, pancreas, intestinal tract, biliary tract, sweat glands, and reproductive tract; the median age at death is 29.1 years, and the predicted survival age of patients with CF is 39.3 years. ${ }^{1,2}$ Morbidity and mortality in patients with CF are associated with a progressive loss of lung function. Episodes of acute worsening, broadly termed "pulmonary exacerbations", are associated with clinical features that include increased cough, sputum production, shortness of breath, chest pain, loss of appetite, loss of weight, and a decline in lung function. ${ }^{3}$ Recurrent PEx events are associated with a permanent decline in lung function, an increased rate of subsequent PEx, and premature mortality. ${ }^{4,5}$ Recurring PEx events diminish health-related quality of life and cause significant interruptions in work, school, and family life. , $^{4,7}$

Management of $\mathrm{CF}$ requires intensive health care resource utilization due, in particular, to exacerbations that often require lengthy hospitalizations of a week or more. ${ }^{8-11}$ Patients with CF in the USA who experience $\geq 1$ exacerbation spend on average 20.0 days in the hospital each year for treatment of exacerbations. ${ }^{1}$ With the exception of CFTR modulators that address the underlying cause of the disease, treatments largely remain targeted at symptoms and physiologic manifestations of CFTR dysfunction. ${ }^{12,13}$

In the USA, CF affects approximately 30,000 individuals. ${ }^{1}$ Approximately half of the US patients with CF are covered by publicly funded programs for people with low incomes. Medicaid (or state-funded health insurance), the largest public health insurance, provides health coverage for $55.2 \%$ of those with CF aged $<18$ years, $43.3 \%$ of those who are aged $18-25$ years, and $27.4 \%$ of those aged $\geq 26$ years. ${ }^{1}$ While it is well understood that managing $\mathrm{CF}$ is a daily commitment for patients and resource-intensive for the health care system, limited data exist on frequency of PEx, health care resource utilization, and the overall burden of disease related to $\mathrm{CF}$ among Medicaid beneficiaries. The goal of this analysis was to describe the overall burden of CF in this population, particularly in terms of the incidence of PEx episodes and their associated costs as well as IP admissions, antibiotic use, and overall health care resource utilization.

\section{Methods \\ Data source}

This retrospective, observational cohort study utilized medical and pharmacy claims data from the Truven Health MarketScan ${ }^{\circledR}$ Medicaid Multi-State Database. The database includes medical and pharmaceutical claims for approximately 10 million individuals annually, $<65$ years of age, from geographical regions throughout the USA, in both managed Medicaid and Medicaid fee-for-service plans. The database links medical claims to retail and mail-order prescription drug claims and person-level data through unique identifiers. No identifiable protected health information was extracted or accessed during the study, pursuant to the US HIPAA. Because the study did not involve the collection, use, or transmittal of individually identifiable data, and due to the compliance of this study with HIPAA, patient consent and institutional review board approval to conduct this study were not necessary.

\section{Patient identification and inclusion criteria}

Health care resource utilization claims over the patients' most recent 12-month enrollment period between January 1, 2012, and June 30, 2014, were analyzed for all patients meeting the inclusion criteria. Patients with $\geq 1$ IP or $\geq 2$ OP claims (at least 30 days apart) with ICD-9-CM: 277.0x for CF between January 2010 and June 2014 were identified. Among these patients, the most recent 12 months of continuous Medicaid enrollment with both medical and pharmacy benefits was evaluated, with at least $1 \mathrm{CF}$-related claim required during this 12 -month period. Patients with $<12$ months of continuous health plan enrollment with both medical and pharmacy benefits were excluded, as were patients aged $<6$ years at the start of the 12-month continuous enrollment period.

\section{Outcome measures}

The study end points included PEx events (number and proportion of patients), IP admissions, length of stay (per IP episode and annum), IV and oral antibiotic use, and health care costs associated with PEx episodes as well as overall cost of care. PEx events were identified in the claims data using a previously developed algorithm. ${ }^{11}$ PEx events were identified as follows: 1) an IP admission with a diagnosis of respiratory infection or CF with pulmonary manifestations; 2) use of 
OP IV antibiotics; or 3) use of only oral antibiotics that are typically used for acute CF treatment. This latter category included events during which patients received a course of exclusively oral antibiotics without any IP admission or IV use. Qualifying PEx identifiers were considered part of the same episode if $\leq 7$ days elapsed between the end of the first identifier (ie, discharge date on IP admission) and the start of the next identifier (ie, start date of an oral antibiotic). For health care resource utilization, rates and lengths of IP admissions, ER visits, OP visits, and medication use were calculated. Total health care costs were categorized by IP, OP, and pharmacy costs and described both over the 12-month study period and during individual PEx events. Health care costs were calculated using the paid amount on fully adjudicated health insurance claims and were reported in 2014 US dollars.

\section{Analysis}

All study measures were summarized using descriptive statistics. Means (SD) were computed for continuous variables, and frequencies $(\%)$ were computed for categorical variables. All study outcomes were stratified by age groups (6-11 years, 12-17 years, 18-26 years, 27-34 years, $\geq 35$ years). Statistical significance was established at the $p<0.05$ level and evaluated using two-sample $t$-test or 1-way analysis of variance for continuous measures and the chi-square test for categorical variables.

\section{Results}

\section{Patient demographic and clinical characteristics}

In total, 1196 patients met the 12-month continuous enrollment and age criteria during the study period (Figure S1). More than half of the patients were $<18$ years $(64.6 \%)$, and mean (SD) patient age was 16.1 (8.8) years (Table 1).

A high prevalence of comorbid conditions, such as pancreatic insufficiency $(78.8 \%$, based on prescription claims for digestive and pancreatic enzymes), pulmonary infection $(37.8 \%)$, asthma $(31.7 \%)$, sinus disease $(27.8 \%)$, diabetes (25.5\%), bronchiectasis (19\%), and depression (14.7\%), was identified among the claims data for Medicaid-insured patients with $\mathrm{CF}$, many of which were nonpulmonary clinical manifestations commonly associated with CF (Table 1). High prescription medication use was also observed with a mean (SD) of 20.2 (12.4) unique medications during the 12-month study period $($ median $=18$, interquartile range $=12-26)$. The most commonly prescribed medications in the population were antibiotics $(92.4 \%)$, bronchodilators $(87.1 \%)$, digestive/pancreatic enzymes (78.8\%), mucolytics (71.5\%),
Table I Demographic characteristics, comorbid conditions, and medication use among Medicaid-insured patients with CF (12-month study period)

\begin{tabular}{|c|c|}
\hline Parameter & Patients $(\mathrm{N}=1196)$ \\
\hline Age, mean (SD) (years) & I6.I (8.8) \\
\hline \multicolumn{2}{|l|}{ Age group, n (\%) (years) } \\
\hline $6-11$ & $424(35.5)$ \\
\hline $12-17$ & $348(29.1)$ \\
\hline $18-26$ & $306(25.6)$ \\
\hline $27-34$ & $80(6.7)$ \\
\hline$\geq 35$ & $38(3.2)$ \\
\hline \multicolumn{2}{|l|}{ Sex, n (\%) } \\
\hline Male & $619(51.8)$ \\
\hline Female & $577(48.2)$ \\
\hline \multicolumn{2}{|l|}{ Race/ethnicity, n (\%) } \\
\hline White & $766(64.0)$ \\
\hline Black & $84(7.0)$ \\
\hline Hispanic & $35(2.9)$ \\
\hline Other/unknown & $3 I I(26.0)$ \\
\hline \multicolumn{2}{|l|}{ Comorbidities, $\mathrm{n}(\%)^{\mathrm{b}, \mathrm{c}}$} \\
\hline Pancreatic insufficiency ${ }^{d}$ & $942(78.8)$ \\
\hline Pulmonary infection & $452(37.8)$ \\
\hline Asthma & $379(31.7)$ \\
\hline Sinus disease & $333(27.8)$ \\
\hline Diabetes & $305(25.5)$ \\
\hline Bronchiectasis & $227(19.0)$ \\
\hline Nausea/vomiting & $188(15.7)$ \\
\hline Depression & $176(14.7)$ \\
\hline Constipation & $172(14.4)$ \\
\hline Anxiety & I $48(12.4)$ \\
\hline \multicolumn{2}{|l|}{ Medication use, n (\%) } \\
\hline Antibiotics & $1105(92.4)$ \\
\hline Oral & $1053(88.0)$ \\
\hline IV & $643(53.8)$ \\
\hline Inhaled & $580(48.5)$ \\
\hline Bronchodilators & $1042(87.1)$ \\
\hline Digestive or pancreatic enzymes & $942(78.8)$ \\
\hline Mucolytics & $855(71.5)$ \\
\hline Corticosteroids & $778(65.1)$ \\
\hline GERD medications & $774(64.7)$ \\
\hline Anti-inflammatory agents & $565(47.2)$ \\
\hline Hypertonic salines & $453(37.9)$ \\
\hline Opioids & $383(32.0)$ \\
\hline Constipation treatments & $285(23.8)$ \\
\hline Vitamins & $26 \mathrm{I}(21.8)$ \\
\hline Antidepressants & $244(20.4)$ \\
\hline Antidiabetes agents & $229(19.1)$ \\
\hline Antifungals & $214(17.9)$ \\
\hline Anxiolytics & $161(13.5)$ \\
\hline Ivacaftor & $43(3.6)$ \\
\hline
\end{tabular}

Notes: apercentages may not add up to 100 due to rounding. ${ }^{\text {b}}$ Comorbidities occurring in $\geq 10 \%$ of the population are included in this table. ${ }^{c}$ Conditions reported based on ICD-9-CM codes. ${ }^{d}$ Reported based on prescription claims for digestive and pancreatic enzymes.

Abbreviations: CF, cystic fibrosis; GERD, gastroesophageal reflux disease; IV, intravenous; ICD-9-CM, International Classification of Diseases, Ninth Revision, Clinical Modification; SD, standard deviation. 
corticosteroids (65.1\%), and gastroesophageal reflux disease medications (64.7\%).

\section{PEx-associated health care resource utilization and costs}

Approximately $90 \%$ of patients had at least 1 PEx event in the 12-month follow-up, a rate consistently observed across all age groups (Figure 1). Half (50.7\%) of all patients with a PEx event received IV antibiotics, and $42.8 \%$ of those with a PEx event required an IP admission with a mean (SD) length of stay of 10.0 (5.9) days.
Recurrent PEx events were frequent in this population, with half (55.7\%) having 3 PEx events and $38.3 \%$ experiencing $\geq 4$ PEx events over the 12-month follow-up period (Figure 2A), with a mean (SD) of 3.1 (2.3) PEx events per patient (Figure 2B). Additionally, the number of recurrent PEx events was higher in older age groups.

Mean (SD) health care costs during a PEx event were US\$75,623 (US\$205,236), driven by IP costs of US $\$ 58,468$ (US\$197,046), and followed by OP costs (US\$2882 [US\$7430]), office visits (US\$233 [US\$314]), and ER visits (US\$169 [US\$670]). Mean (SD) pharmacy costs were

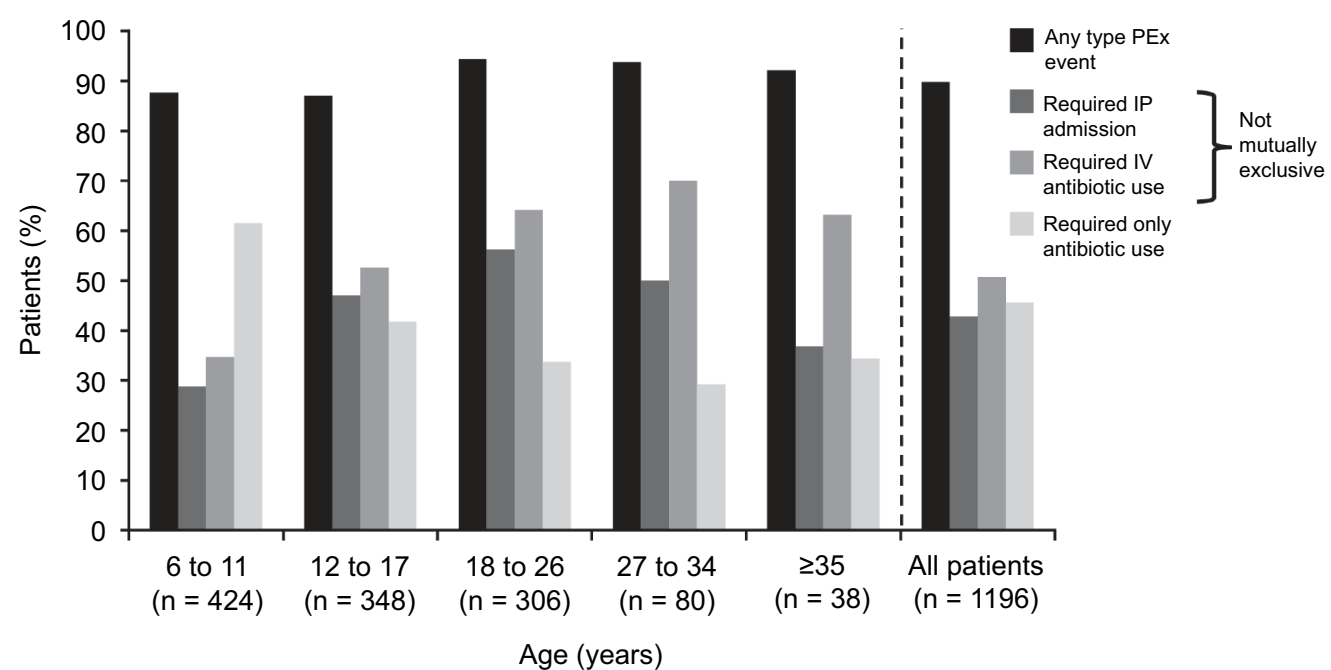

Figure I Medicaid-insured patients with CF with PEx events by PEx event type (over 12 months, by age group). Abbreviations: CF, cystic fibrosis; IP, inpatient; IV, intravenous; PEx, pulmonary exacerbation.
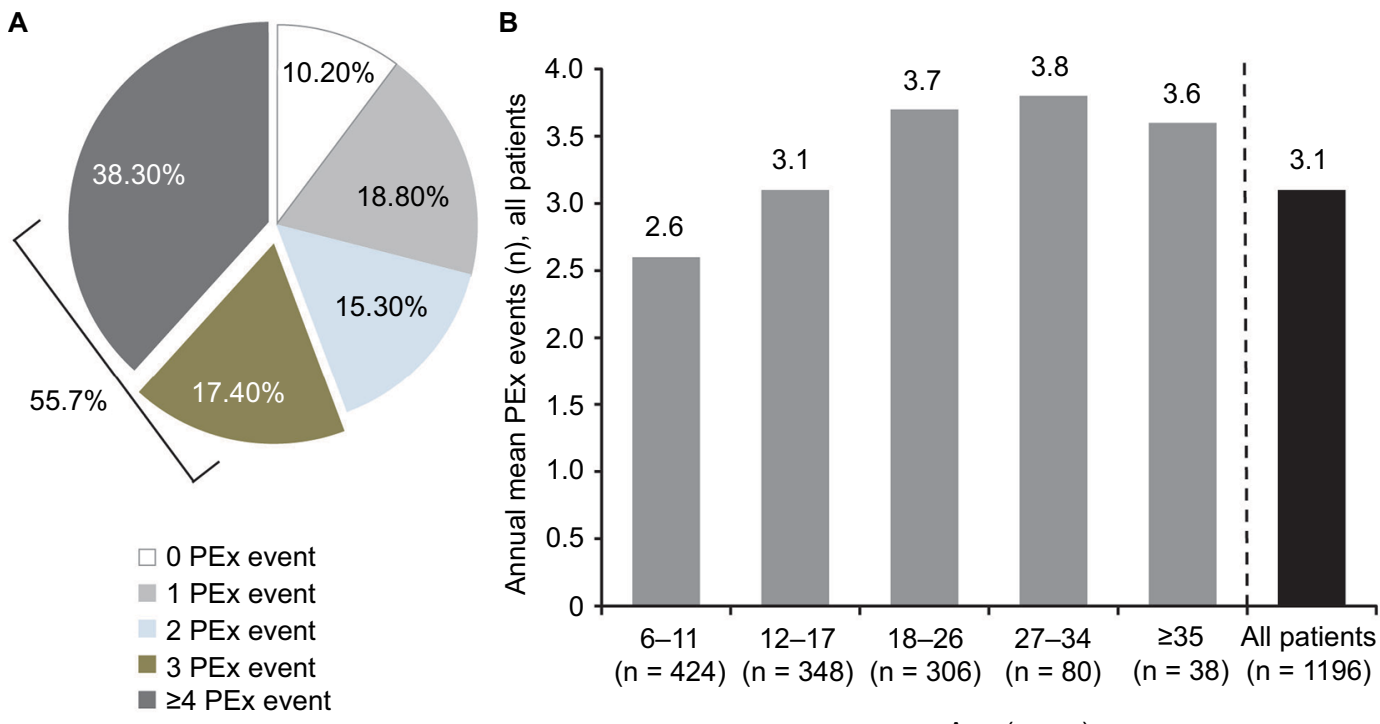

Age (years)

Figure 2 Proportion of Medicaid-insured patients with CF with any PEx event in the total population (N=II96): (A) over I2 months and (B) mean number of PEx events in Medicaid-insured patients with CF over 12 months, by age group.

Abbreviations: CF, cystic fibrosis; PEx, pulmonary exacerbation. 
US\$14,273 (US\$21,415), and mean (SD) antibiotic costs were US\$5716 (US\$10,555). Among mean (SD) antibiotic costs, inhaled was highest at US\$3934 (US\$7961), followed by oral at US\$1270 (US\$4293), and lastly IV at US\$320 (US\$1757).

PEx events lasted a mean (SD) of 29.3 (32.4) days. Mean (SD) costs during a PEx event increased steadily with age up to age 34 , increasing from US\$44,589 (US\$139,024) among patients aged 6-11 years to US\$116,169 (US\$387,752) for patients aged 27-34 years; mean (SD) costs during a PEx event were US\$62,947 (US\$134,749) for patients $\geq 35$ years (Figure 3). A similar relationship was observed in mean (SD) length of distinct PEx events, increasing from 20.7 (23.2) days among patients aged 6-11 years to 27.1 (28.9) days among patients aged 12-17 years, 35.9 (35.9) days among patients aged 18-26 years, and 38.9 (47.3) days among patients aged 27-34 years but decreasing to 19.6 (21.4) days in patients $\geq 35$ years.

\section{Overall health care resource utilization}

Health care resource utilization was high among Medicaidinsured patients. Nearly half (47.2\%) of the study population had an IP admission, with a mean (SD) length of stay of 9.7 (11.0) days (Table 2). The proportion of patients with an IP stay was nearly double among the 27- to 34-year age group (61.3\%) compared with young children aged 6-11 years (32.1\%). More than 1 in 4 patients $(26.8 \%)$ had a subsequent IP admission during the 12-month follow-up period (Table 2) totaling a mean (SD) of 29.1 (34.3) hospital days per patient over the 12-month period. At least half of all patients with $C F$ aged $\geq 18$ years had an ER visit during the follow-up period, as did 1 in 3 patients with CF aged 6-11 years (Table 2). The 3 most frequent specific procedure utilizations were testing $(86.3 \%)$, respiratory therapies $(21.7 \%)$, and nasal polyp removal $(7.8 \%)$, and the 3 most frequent specific medical device utilizations were nebulizers (17.9\%), home oxygen (8.4\%), and metered dose inhaler (3.4\%).

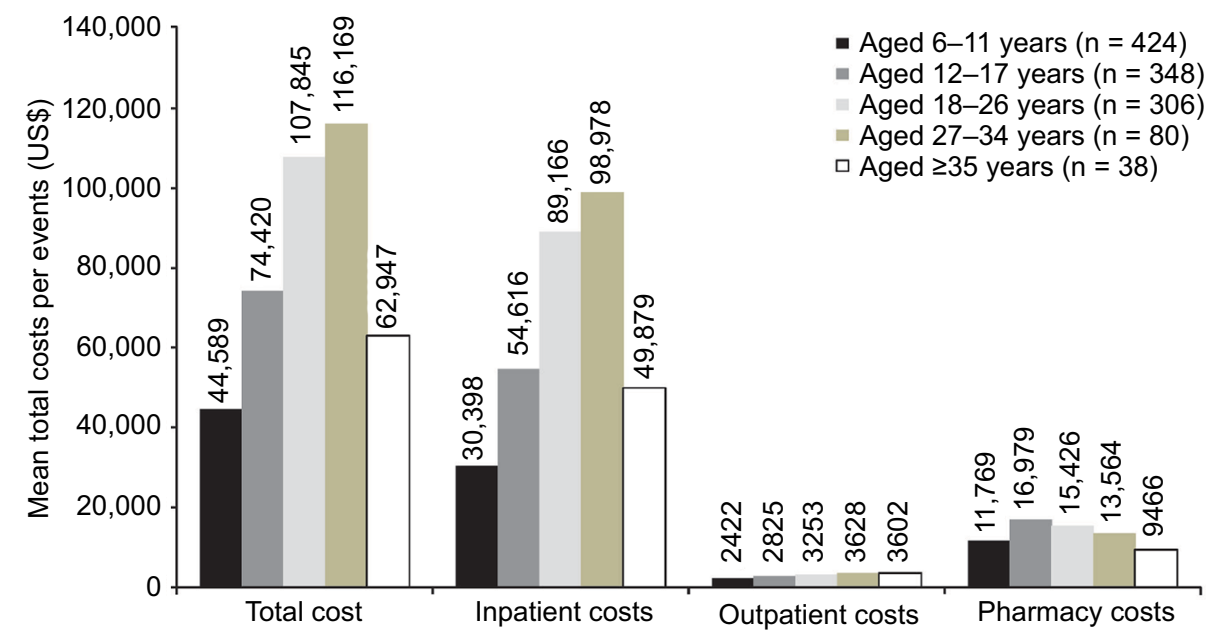

Figure 3 Mean total costs/PEx events of Medicaid-insured patients with CF (over 12 months, by age group).

Abbreviations: $\mathrm{CF}$, cystic fibrosis; PEx, pulmonary exacerbation.

Table 2 Summary of overall health care resource utilization in Medicaid-insured patients with CF over 12 months

\begin{tabular}{|c|c|c|c|c|c|c|}
\hline Health care resource utilization & $\begin{array}{l}\text { Aged } \\
\text { 6-II years } \\
(n=424) \\
\end{array}$ & $\begin{array}{l}\text { Aged } \\
\text { I2- } 17 \text { years } \\
(n=348)\end{array}$ & $\begin{array}{l}\text { Aged } \\
\text { I 8-26 years } \\
(n=306)\end{array}$ & $\begin{array}{l}\text { Aged } \\
27-34 \text { years } \\
(n=80)\end{array}$ & $\begin{array}{l}\text { Aged } \\
\geq 35 \text { years } \\
(n=38) \\
\end{array}$ & $\begin{array}{l}\text { All patients } \\
(\mathrm{N}=1196)\end{array}$ \\
\hline Patients with an IP admission, \% & 32.1 & 50.0 & 60.8 & 61.3 & 52.6 & 47.2 \\
\hline Mean total IP days, $n$ (SD) & $21.4(29.2)$ & $26.8(29.7)$ & $35.0(37.5)$ & $37.2(46.3)$ & $25.1(27.9)$ & $29.1(34.3)$ \\
\hline Mean IP admissions per person, $\mathrm{n}(\mathrm{SD})$ & $2.0(1.4)$ & $2.3(1.8)$ & $3.6(3.1)$ & $3.6(3.4)$ & $3.2(2.4)$ & $2.8(2.5)$ \\
\hline Mean length of stay per IP admission, n (SD) (days) & $10.4(19.5)$ & $10.5(6.5)$ & $8.6(4.9)$ & $10.0(7.6)$ & $7.7(8.1)$ & $9.7(11.0)$ \\
\hline Patients with an IP readmission, \% & 13.9 & 27.3 & 40.5 & 36.3 & 36.8 & 26.8 \\
\hline Patients with an ER visit, \% & 33.7 & 40.8 & 52.6 & 62.5 & 63.2 & 43.5 \\
\hline $\begin{array}{l}\text { Mean CF-related office visits for patients with an } \\
\text { office visit, } n(S D)\end{array}$ & $7.0(4.9)$ & $6.9(5.4)$ & $5.9(4.8)$ & $5.7(4.5)$ & $3.7(4.5)$ & $6.6(5.0)$ \\
\hline
\end{tabular}

Note: a Defined as an outpatient office visit with a CF code in any diagnosis position on the claim.

Abbreviations: CF, cystic fibrosis; ER, emergency room; IP, inpatient; SD, standard deviation. 


\section{Discussion}

Medicaid beneficiaries with $\mathrm{CF}$ in our analysis showed a substantial disease burden with respect to comorbidities, PEx events, and health care resource utilization. Comorbidities included both pulmonary (ie, pulmonary infection, sinus disease, asthma) and nonpulmonary conditions (ie, pancreatic insufficiency, diabetes, depression, anxiety). PEx events were frequent $-90 \%$ of all patients had at least 1 PEx event, and about half (42.8\%) of these patients required hospitalization or treatment with an IV antibiotic (50.7\%). More than half (55.7\%) had $\geq 3$ exacerbations.

High disease burden for CF in this current Medicaid population is consistent with previous literature describing outcomes in the 1990s in patients with CF receiving Medicaid (evaluated as a surrogate for lower socioeconomic status). ${ }^{14-16}$ One of the earliest studies of $\mathrm{CF}$ and Medicaid coverage (in patients $<21$ years of age) reported lower pulmonary function throughout childhood, higher rates of hospitalization, and longer hospital stays compared with a non-Medicaid cohort. Several other parameters (IV antibiotic use at home, clinic visits, and age at diagnosis) did not differ between the 2 populations in this single-institution study. ${ }^{14} \mathrm{~A}$ second retrospective analysis of patients (aged $<20$ years followed from 1986 to 1994) using CFFPR data compared outcomes for patients covered by Medicaid with those never covered by Medicaid. Patients receiving Medicaid were significantly more likely than the non-Medicaid sample to experience a PEx event (adjusted relative risk = 2.38; 95\% CI, 2.11, 2.69; $p<0.001$ ) and to die (adjusted relative risk $=3.70 ; 95 \% \mathrm{CI}, 3.06,4.46 ; p<0.001$ ), with increased mortality in this study attributed to baseline pulmonary function. Treatment of PEx with IV antibiotics was reported for $44.5 \%$ of these Medicaid patients (vs 28.6\% of the non-Medicaid sample), a value consistent with our findings. A similar proportion of Medicaid patients were hospitalized for PEx (43.4\% vs $25.9 \%$ of the non-Medicaid sample), also consistent with our findings. ${ }^{16}$

Prior analyses evaluating disease burden in CF provide additional context for those reported here. A recent study among a commercially insured population of $>3000$ patients with CF (mean age 27 years) found that $83.4 \%$ of patients had at least 1 PEx event during the 12-month assessment period, which is generally consistent with our annual PEx rate of $90 \%$. In this same study, a smaller proportion of patients had $\geq 3$ PEx events (43.0\% vs 55.7\%) and PEx requiring IP hospitalization ( $28.2 \%$ vs $42.8 \%$ ) when compared with our Medicaid population and using the same definition for PEx events. ${ }^{17}$
Additional real-world data on PEx among patients with CF are primarily drawn from the CFFPR ( $n=28,676$ in the 2014 report). However, PEx events as defined by the CFFPR do not include exacerbations treated with oral antibiotics, a practice especially common in children and included as a PEx event in our analysis. ${ }^{18}$ The annual rate of PEx events (defined by the CFFPR as treatment with IV antibiotics in the hospital or at home) has remained at nearly one-half of adults and one-third of children, with no reduction over the past decade. ${ }^{1}$ In 2014, 35.2\% of those in the CFFPR had an exacerbation requiring an IV antibiotic; information from the CFFPR on oral antibiotic use for the treatment of PEx is not available. ${ }^{1}$ The mean number of hospital days per year for CFFPR participants hospitalized with a PEx event was 20.0 days vs 29.1 days in our Medicaid cohort. If PEx events in this Medicaid cohort are limited to those treated in hospital or with IV antibiotics (59.4\%), rates are higher than those reported for the CFFPR. ${ }^{19}$

When evaluating our findings, it may be noted that the Medicaid cohort described here was younger by several years than what might be considered a representative population with CF characterized by the CFFPR in the US in 2014 (mean age 16.1 years vs 20.6 years, respectively). Given the natural course of disease in $\mathrm{CF}$, which includes high rate of mortality and lower life expectancy, the number of $\mathrm{CF}$ patients $>35$ years of age was small in this observational research. Thus, the small number of patients in the subgroup $\geq 35$ years of age makes their data difficult to interpret. With 2 exceptions (CF-related office visits and length of stay per IP admission), overall health care utilization increased with increasing age for Medicaid-insured patients in this study. The number of PEx events per year showed a modest rise with increasing age such that children and young adults had almost as many PEx events per year (2.6 and 3.1, respectively) as adults (approximately 3.7). With advancing age, there was a decline in the number of PEx events requiring treatment with oral antibiotics and an increase in the number of PEx events requiring treatment with IV antibiotics.

This study highlights several unmet needs and areas for future research. There is an unmet need to improve understanding on prevention of PEx; treatment adherence as well as effectiveness of other interventions to prevent PEx should be considered for further research. There is also unmet need to understand the burden of illness utilization of children with $\mathrm{CF}<6$ years. As it is understood that the utilization of children $<6$ years with $\mathrm{CF}$ can differ compared to children $\geq 6$ years due to the natural course of the disease, study design to accurately capture the burden of illness should be quite 
different from the current study. This is an important area for further research. Discrepancies in patient ages, along with variations in definitions of PEx and differing detection methods (eg, claims-based algorithm vs patient self-report or medical record review), make comparisons across studies challenging. However, results of the current analysis largely agree with prior studies showing that Medicaid patients with CF experience a high degree of disease morbidity and increased risk of PEx often associated with longer hospital stays and IV antibiotic use.

\section{Limitations}

Although administrative claims data are an important data source for real-world evidence studies, this study is subject to inherent limitations in using these data, such as a lack of detailed clinical information. ${ }^{20}$ In the absence of clinical information, PEx events were identified using a previously developed algorithm based on ICD-9-CM diagnosis codes and treatment utilization patterns typical of PEx events. ${ }^{11}$ This study is limited to Medicaid enrollees covered under fee-for-service and managed care plans and may not be generalizable to the general $\mathrm{CF}$ population, to patients with other insurance, or to those without health insurance coverage. Diagnosis coding for CF in the Medicaid database does not contain information on genotype; hence, study data on specific subpopulations of patients with CF were not available. Sample sizes for older age groups, especially those $\geq 35$ years, were too small for utilization analysis, and the 12-month observational period for this study may not reflect long-term costs and utilizations. This burden of illness study is focused on patients $\geq 6$ years and may not be generalizable to patients $<6$ years of age who may have different HCRU patterns. Finally, this analysis is limited to the economic outcomes borne by a health plan and does not include indirect costs, uncovered services, or caregiver burden.

\section{Conclusion}

This retrospective, population-based claims analysis provides a current characterization of the burden of CF among Medicaid beneficiaries in terms of PEx events, hospital admissions, antibiotic use, and overall health care resource utilization by age groupings. The study underscores the high rates of recurrent PEx events among Medicaid beneficiaries resulting in increased hospitalizations per year, longer hospital stays, and treatment with IV antibiotics. The number of yearly PEx events in our Medicaid cohort is approximately 2-3 - even in younger patients with $\mathrm{CF}$ - and more than one-half of patients experienced $\geq 3$ PEx events per year. As PEx events lead to a higher risk of permanent lung function loss, treatment strategies to prevent PEx events are especially important for this population.

\section{Abbreviations}

$\mathrm{CF}$, cystic fibrosis CFFPR, Cystic Fibrosis Foundation Patient Registry

CFTR, CF transmembrane conductance regulator

$\mathrm{CI}$, confidence interval

ER, emergency room

GERD, gastroesophageal reflux disease

HCRU, health care resource utilization

HIPAA, Health Insurance Portability and Accountability Act ICD-9-CM, International Classification of Diseases, Ninth Revision, Clinical Modification

IP, inpatient

IV, intravenous

OP, outpatient

PEx, pulmonary exacerbation

$\mathrm{SD}$, standard deviation

\section{Acknowledgments}

This study was funded by Vertex Pharmaceuticals Incorporated. The authors would like to thank Jaime Rubin Cahill for providing the algorithm to determine PEx. Jamie Rubin Cahill is an employee of Vertex Pharmaceuticals Incorporated and may own stock or stock options in that company. Editorial coordination and support were provided by Dhrupad Patel, PharmD, and Stephen Parker, ELS. Dhrupad Patel is an employee of Vertex Pharmaceuticals Incorporated and may own stock or stock options in that company. Stephen Parker is a former employee of Vertex Pharmaceuticals Incorporated and may own stock or stock options in that company. Editorial and graphic support were provided by Edwin Thrower, PhD, and Paula Stuckart. Edwin Thrower and Paula Stuckart are employees of Ashfield Healthcare Communications, which received funding from Vertex Pharmaceuticals Incorporated. The abstract of this paper was presented at the 29th Annual North American Cystic Fibrosis Conference (NACFC) as a poster presentation with interim findings. The NACFC poster's abstract was published in "Poster Session Abstracts" in Pediatric Pulmonology (2015;50(S41):447). The encore abstract to the NACFC abstract was presented at the Academy of Managed Care Pharmacy (AMCP) 2016 Annual Meeting as a poster presentation with interim findings. The AMCP poster's abstract was published in "Meeting Abstracts" in Journal of Managed Care \& Specialty Pharmacy (2016;22(4 Suppl):S55). 


\section{Data sharing statement}

All data analyzed during this study are included in this published article (and its supplementary Figure S1).

\section{Author contributions}

$\mathrm{MH}, \mathrm{PH}$, and GSS had the idea for and designed the study. MMB and BLL collected, analyzed, and interpreted data. MH, $\mathrm{PH}$, and GSS analyzed and interpreted data. All the authors wrote and revised the article and agree to be accountable for all aspects of the work.

\section{Disclosure}

MH is an employee of Vertex Pharmaceuticals Incorporated and may own stock or stock options in that company. MMB and BLL are employees of Truven Health Analytics. GSS has served on advisory boards for Gilead, Genentech, Novartis, and Vertex Pharmaceuticals Incorporated. PH is a former employee of Vertex Pharmaceuticals Incorporated and may own stock or stock options in that company. The authors report no other conflicts of interest in this work.

\section{References}

1. Cystic Fibrosis Foundation. Patient registry annual data report. 2014. Available from: https://www.cff.org/2014-Annual-Data-Report.pdf. Accessed July 5, 2016.

2. NIH. CFTR. Genetics Home Reference. 2015. Available from: http:// ghr.nlm.nih.gov/gene/CFTR. Accessed July 5, 2016.

3. Bhatt JM. Treatment of pulmonary exacerbations in cystic fibrosis. Eur Respir Rev. 2013;22(129):205-216.

4. Britto MT, Kotagal UR, Hornung RW, Atherton HD, Tsevat J, Wilmott RW. Impact of recent pulmonary exacerbations on quality of life in patients with cystic fibrosis. Chest. 2002;121(1):64-72.

5. Liou TG, Adler FR, Fitzsimmons SC, Cahill BC, Hibbs JR, Marshall BC. Predictive 5-year survivorship model of cystic fibrosis. Am J Epidemiol. 2001;153(4):345-352.

6. Abbott J, Holt A, Hart A, et al. What defines a pulmonary exacerbation? The perceptions of adults with cystic fibrosis. J Cyst Fibros. 2009;8(5):356-359.

7. Abbott J, Holt A, Morton AM, et al. Patient indicators of a pulmonary exacerbation: preliminary reports from school aged children map onto those of adults. J Cyst Fibros. 2012;11(3):180-186.
8. Briesacher BA, Quittner AL, Fouayzi H, Zhang J, Swensen A. Nationwide trends in the medical care costs of privately insured patients with cystic fibrosis (CF), 2001-2007. Pediatr Pulmonol. 2011;46(8):770-776.

9. Krauth C, Jalilvand N, Welte T, Busse R. Cystic fibrosis: cost of illness and considerations for the economic evaluation of potential therapies. Pharmacoeconomics. 2003;21(14):1001-1024.

10. O’Sullivan AK, Sullivan J, Higuchi K, Montgomery AB. Health care utilization \& costs for cystic fibrosis patients with pulmonary infections. Manag Care. 2011;20(2):37-44.

11. Rubin JL, Thayer S, Watkins AK, Wagener J, Hodgkins P, Schechter MS. Frequency and costs of pulmonary exacerbations in patients with cystic fibrosis. Paper presented at: The 38th European Cystic Fibrosis Conference; June 10-13, 2015; Brussels.

12. Marigowda G, Liu F, Waltz D. Effect of bronchodilators in healthy individuals receiving lumacaftor in combination with ivacaftor. Pediatr Pulmonol. 2014;49(Suppl 38):S307.

13. McColley SA, Konstan MW, Ramsey BW, et al. Association between changes in percent predicted $\mathrm{FEV}_{1}$ and incidence of pulmonary exacerbations, including those requiring hospitalization and/or IV antibiotics, in patients with CF treated with lumacaftor in combination with ivacaftor. Pediatric Pulmonol. 2015;50(Suppl 41):282.

14. Schechter MS, Margolis PA. Relationship between socioeconomic status and disease severity in cystic fibrosis. J Pediatr. 1998;132(2): 260-264.

15. Schechter MS, McColley SA, Silva S, Haselkorn T, Konstan MW, Wagener JS; Investigators and Coordinators of the Epidemiologic Study of Cystic Fibrosis; North American Scientific Advisory Group for ESCF. Association of socioeconomic status with the use of chronic therapies and healthcare utilization in children with cystic fibrosis. J Pediatr. 2009;155(5):634-639.e631-e634.

16. Schechter MS, Shelton BJ, Margolis PA, Fitzsimmons SC. The association of socioeconomic status with outcomes in cystic fibrosis patients in the United States. Am J Respir Crit Care Med. 2001;163(6): 1331-1337.

17. Hassan M, Bonafede M, Limone B, Hodgkins P, Sawicki G. The burden of cystic fibrosis: pulmonary exacerbations and healthcare resource utilization in a commercially insured US population. Paper presented at: ISPOR 21st Annual International Meeting; May 21-25, 2016; Washington, DC.

18. Wagener JS, Rasouliyan L, VanDevanter DR, et al; Investigators and Coordinators of the Epidemiologic Study of Cystic Fibrosis. Oral, inhaled, and intravenous antibiotic choice for treating pulmonary exacerbations in cystic fibrosis. Pediatr Pulmonol. 2013;48(7): 666-673.

19. Cystic Fibrosis Foundation. Patient registry annual data report. 2013. Available from: https://www.cff.org/2013_CFF_Patient_Registry_ Annual_Data_Report.pdf. Accessed July 5, 2016.

20. Motheral B, Brooks J, Clark MA, et al. A checklist for retrospective database studies - report of the ISPOR Task Force on Retrospective Databases. Value Health. 2003;6(2):90-97. 


\section{Supplementary material}

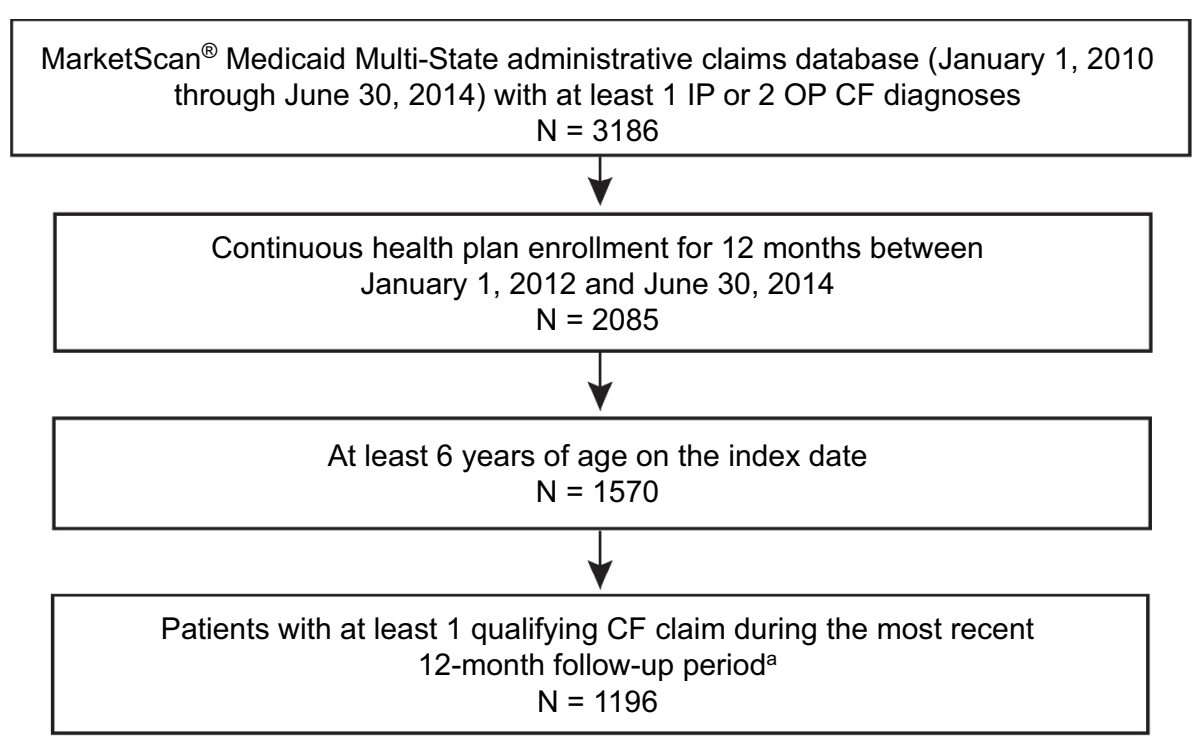

Figure SI CONSORT diagram showing patient selection.

Note: at least I IP, OP, or ER claim with a diagnosis of CF (277.0x).

Abbreviations: CF, cystic fibrosis; ER, emergency room; IP, inpatient; OP, outpatient.

ClinicoEconomics and Outcomes Research is an international, peerreviewed open-access journal focusing on health technology assessment, pharmacoeconomics and outcomes research in the areas of diagnosis, medical devices, and clinical, surgical and pharmacological intervention. The economic impact of health policy and health systems organization also constitute important areas of coverage. The manuscript management system is completely online and includes a very quick and fair peer-review system, which is all easy to use. Visit http://www.dovepress.com/testimonials.php to read real quotes from published authors. 